\title{
Efeito do probiótico sobre o desempenho, rendimento de carcaça e exigências nutricionais de proteína bruta de codornas de corte ${ }^{1}$
}

\section{Luciana Kazue Otutumi ${ }^{*}$, Antonio Claudio Furlan ${ }^{3}$, Elias Nunes Martins ${ }^{3}$, Elis Regina de Moraes Garcia ${ }^{4}$, Ana Paula Silva Ton ${ }^{2}$, Ana Carolina Monteiro ${ }^{2}$}

\author{
${ }^{1}$ Pesquisa financiada pelo CNPq. \\ 2 Programa de Pós-Graduação em Zootecnia da UEM. \\ ${ }^{3}$ Departamento de Zootecnia da UEM, Avenida Colombo, 5790, CEP: 87020-900, Maringá, PR \\ 4 Departamento de Zootecnia da Universidade Estadual do Mato Grosso do Sul, Unidade Universitária de Aquidauana. Rodovia Aquidauana \\ Cera, km 12, CEP: 79200-000, Aquidauana, MS.
}

RESUMO - Para avaliar o efeito do probiótico (Lactobacillus sp.) associado a diferentes níveis de proteína bruta (PB) sobre o desempenho, as exigências nutricionais de $\mathrm{PB}$, o rendimento de carcaça e de cortes de codornas de corte, foram utilizadas 2.304 codornas de corte, distribuídas em esquema fatorial $2 \times 4$ (com e sem probiótico e 15, 20, 25 ou 30\% de PB), com duas repetições por nível de $\mathrm{PB}$, repetido duas vezes no tempo (dois períodos experimentais), totalizando 32 unidades experimentais. A adição do probiótico reduziu o consumo de ração e melhorou a conversão alimentar no período de 1 a 7 dias de idade. De acordo com os pesos médios do modelo Linear Response Plateau (LRP), aos 7 e aos 14 dias, as estimativas de exigência foram de $27 \%$ de PB e aos 21, 28 e 35 dias, 22 a $24 \%$ de PB. A adição do probiótico não influenciou o rendimento de carcaça e de cortes. Para o rendimento de carcaça, a exigência de PB, de acordo com o modelo quadrático, foi estimada em 23,53\%, mas, pelo modelo LRP, a estimativa reduziu para $17,13 \%$ de PB. Nas condições ambientais em que as codornas foram criadas, a adição do probiótico não influenciou o desempenho, as exigências nutricionais de PB e o rendimento de carcaça de codornas de corte. As exigências de PB para aves de até 14 dias de idade são de $27 \%$ e, após esta idade, reduzem para 22 a $24 \%$.

Palavras-chave: conversão alimentar, lactobacilos, rendimento de perna, viabilidade de criação

\section{Effect of the addition of probiotic on performance, carcass yield and crude protein nutritional requirements of meat quails}

\begin{abstract}
To evaluate the effect of probiotic (Lactobacillus sp.) associated with different crude protein (CP) levels on performance, CP nutritional requirements, carcass and cut yields of meat quails, a total of 2304 meat quails were distributed in a $2 \times 4$ factorial design (with and without probiotic and four CP levels $-15,20,25$ and 30\%), with two replications per treatment, repeated twice in time (two experimental periods), totalizing 32 experimental units. The addition of probiotic decreased the feed intake and improved the feed conversion rate at 1 to 7 days of age. According to the mean weight of the LRP model, at 7 and 14 days, the requirement estimations were of $27 \%$ of CP and at 21,28 and 35 days, the requirements were from 22 to $24 \%$ of CP. The addition of probiotic did not influence carcass and cut yields. For the carcass yield, the $\mathrm{CP}$ requirement, according to the quadratic model, was estimated in $23.53 \%$; however, in relation to LRP, the estimative decrease to $17.13 \%$ of CP. It was possible to conclude that in the environmental conditions evaluated, the addition of probiotic did not influence the performance, CP nutritional requirement and carcass yield of meat quails. The CP requirements for birds of up to 14 days of age were of $27 \%$ and, after this age, there are evidences of reduction to values from 22 to $24 \%$.
\end{abstract}

Key Words: feed conversion, lactobacillus, leg yield, breeding viability

\section{Introdução}

A qualidade da carne de codorna é conhecida desde a antigüidade pelo seu alto conteúdo de proteína e aminoácidos, pela baixa quantidade de gordura e pelo preparo gastronômico fácil e rápido (Barral, 1994). No Brasil, contudo, a coturnicultura de corte é uma atividade ainda pouco difundida, o que implica poucos conhecimentos na área de melhoramento, nutrição e exigências nutricionais, manejo e sanidade, principalmente nas áreas de nutrição. 
Além disso, os dados disponíveis são provenientes, em sua maioria, de literatura estrangeira, obtidos em condições ambientais diferentes das condições climáticas brasileiras (Oliveira et al., 2002).

A alimentação é o principal fator responsável pela resposta das aves e representa $70 \%$ do custo de produção (Murakami \& Ariki, 1998). Logo, as estimativas das exigências nutricionais são essenciais para a formulação de rações de mínimo custo ou de máximo retorno, principalmente quando considerados os níveis de proteína e energia, componentes de maior participação nos custos de produção.

Corrêa et al. (2004a) observaram que a exigência de proteína bruta para máximo ganho de peso de codornas de corte européias era acima de $28 \%$ para o período de 7 a 14 dias, $26 \%$ para o período de 15 a 28 dias e de $24 \%$ para o período de 29 a 35 dias. Com o desenvolvimento da coturnicultura como atividade comercial, as atuais proibições do uso de alguns antibióticos como promotores de crescimento, e as discussões sobre o total banimento de seu uso, é necessário pesquisar produtos que possam ser utilizados como substitutos a esses antibióticos, especialmente os probióticos.

Segundo Fuller (1989), probióticos são produtos constituídos de microrganismos vivos benéficos ao animal hospedeiro por promoverem o equilíbrio da microbiota intestinal.

Em frangos de corte, Mikulec et al. (1999) observaram influência favorável dos probióticos em dietas com deficiência protéica, porém, esse efeito é mais evidente quando há redução dos níveis de metionina, cistina, lisina e/ou triptofano (Dilworth \& Day, 1978; Kos \& Wittner, 1982).

Assim, objetivou-se com este trabalho avaliar o efeito de probióticos à base de Lactobacillus sp. em rações com diferentes níveis de proteína bruta sobre o desempenho, o rendimento de carcaça e as exigências nutricionais de proteína bruta de codornas de corte.

\section{Material e Métodos}

O experimento foi conduzido no Setor de Avicultura da Fazenda Experimental de Iguatemi/FEI/UEM, em dois períodos (de maio a junho e de julho a agosto) de 2005.

Foram utilizadas 2.304 (1.440 no primeiro período e 864 no segundo período) codornas de corte (Coturnix coturnix sp.), machos e fêmeas, no período de 1 a 35 dias de idade. As codornas foram alojadas em boxes de $3,0 \mathrm{~m}^{2}$, em densidade de 30 aves $/ \mathrm{m}^{2}$ no período 1 e de 18 aves $/ \mathrm{m}^{2}$ no período 2, em galpão convencional disposto no sentido leste-oeste, com cobertura de telha francesa, piso de concreto e paredes laterais de alvenaria com $0,40 \mathrm{~m}$ de altura completada com tela de arame até o telhado.

As rações foram formuladas de acordo com as exigências propostas por Barral (1994) e a composição dos alimentos, segundo Rostagno et al. (2005), de forma a serem isocalóricas e isocálcicas, com níveis 15, 20, 25 ou 30\% de proteína bruta (Tabela 1). O nível de $25 \%$ foi o mais próximo do preconizado por Barral (1994), que recomenda 26 a $28 \%$ de PB.

O delineamento experimental foi em esquema fatorial $2 \times 4$ (com e sem probiótico; quatro níveis de proteína), com duas repetições por nível de $\mathrm{PB}$, repetido no tempo, em dois períodos de 35 dias. O probiótico, do fabricante FATEC ${ }^{\circledR}$, foi administrado, via ração, durante a primeira semana experimental, na dosagem de $200 \mathrm{~g} /$ tonelada de ração, e continha em média $1,6 \times 10^{9} \mathrm{ufc} / \mathrm{g}$ de um pool de Lactobacillus sp.

O desempenho das codornas de corte foi avaliado por meio do consumo de ração, do ganho de peso, da conversão alimentar e da viabilidade de criação (número de aves vivas dividido pelo total de aves multiplicado por 100) durante o período experimental.

Para avaliação do rendimento de carcaça e dos cortes cárneos, aos 35 dias de idade foram amostradas ao acaso 20 aves representantes da unidade experimental e de cada

Tabela 1 - Composição das rações experimentais

\begin{tabular}{|c|c|c|c|c|}
\hline \multirow[t]{2}{*}{ Ingrediente } & \multicolumn{4}{|c|}{ Nível de proteína (\%) } \\
\hline & 15 & 20 & 25 & 30 \\
\hline Milho & 75,00 & 61,77 & 44,55 & 27,40 \\
\hline Farelo de soja & 17,50 & 32,91 & 47,60 & 62,14 \\
\hline Farelo de trigo & 3,84 & - & - & - \\
\hline Calcário & 1,10 & 1,04 & 1,05 & 1,07 \\
\hline Fosfato bicálcico & 1,55 & 1,46 & 1,25 & 1,04 \\
\hline Sal comum & 0,40 & 0,40 & 0,40 & 0,40 \\
\hline L-lisina HCL & 0,20 & 0,06 & - & - \\
\hline $\begin{array}{l}\text { Premix vitamínico } \\
+ \text { mineral }\end{array}$ & 0,40 & 0,40 & 0,40 & 0,40 \\
\hline B HT & 0,01 & 0,01 & 0,01 & 0,01 \\
\hline Óleo de soja & - & 1,96 & 4,77 & 7,60 \\
\hline \multicolumn{5}{|l|}{ Valores calculados } \\
\hline $\begin{array}{l}\text { Energia } \\
\text { metabolizável }(\mathrm{kcal} / \mathrm{kg})\end{array}$ & 3.000 & 3.000 & 3.000 & 3.000 \\
\hline Proteína bruta $(\%)$ & 15,00 & 20,00 & 25,00 & 30,00 \\
\hline Cálcio (\%) & 0,90 & 0,90 & 0,90 & 0,90 \\
\hline Fósforo total (\%) & 0,60 & 0,60 & 0,60 & 0,60 \\
\hline Lisina total $(\%)$ & 0,87 & 1,15 & 1,48 & 1,85 \\
\hline $\begin{array}{l}\text { Metionina + cistina } \\
\text { total }(\%)\end{array}$ & 0,64 & 0,79 & 0,91 & 1,04 \\
\hline \multicolumn{5}{|c|}{$\begin{array}{l}\text { * Composição por kg do produto: vit. A - } 2500.000 \mathrm{UI} \text {; vit. } \mathrm{D}_{3}-625.000 \mathrm{UI} \\
\text { vit. E - } 3.750 \mathrm{mg} \text {; vit. } \mathrm{B}_{1}-138 \mathrm{mg} \text {; vit. } \mathrm{B}_{2}-1.250 \mathrm{mg} \text {; vit. } \mathrm{B}_{6}-523 \mathrm{mg} \text {; vit. } \mathrm{B}_{12} \\
5.000 \mathrm{mcg} \text {; vit. } \mathrm{K}_{3}-750 \mathrm{mg} \text {; ácido fólico }-112 \mathrm{mg} \text {; pantotenato de cálcio }-2.000 \mathrm{mg} \\
\text { niacina }-7.500 \mathrm{mg} \text {; metionina }-275.000 \mathrm{mg} \text {; colina }-87.500 \mathrm{mg} \text {; selênio }-63 \mathrm{mg} \\
\text { antioxidante }-2.500 \mathrm{mg} \text {; iodo - } 240 \mathrm{mg} \text {; veículo q.s.p. }-1.000 \mathrm{~g} \text {; zinco }-15.750 \mathrm{mg} \\
\text { ferro }-12.250 \mathrm{mg} \text {; manganês }-19.375 \mathrm{mg} \text {; cobre }-3.900 \mathrm{mg} \text {; cobalto }-50 \mathrm{mg} \text {. }\end{array}$} \\
\hline
\end{tabular}


nível de proteína bruta ou probiótico. As aves foram identificadas individualmente por meio de anilhas numeradas colocados nas patas e submetidas a jejum alimentar de 8 horas, com água à vontade, até o momento do carregamento.

Após a pesagem individual, o abate foi realizado por degola completa entre os ossos occipital e atlas. As aves foram escaldadas por 15 a 20 segundos a $55-60^{\circ} \mathrm{C}$, depenadas e evisceradas manualmente. As carcaças foram pesadas e suas partes separadas e pesadas para determinação dos rendimentos de peito, pernas, dorso e asa.

No cálculo do rendimento de carcaça, foi considerado o peso da carcaça eviscerada (sem pés, cabeça e gordura abdominal) em relação ao peso vivo. O rendimento de cortes cárneos foi calculado considerando o rendimento de peito inteiro com pele, pernas (coxa e sobrecoxa com pele), dorso e asas, calculado em relação ao peso da carcaça eviscerada.

A gordura abdominal foi constituída do tecido adiposo presente em torno da cloaca, bolsa cloacal e moela, do proventrículo e dos músculos abdominais adjacentes, conforme descrito por Smith (1993), e também foi calculada em relação ao peso da carcaça eviscerada.

A análise estatística das variáveis estudadas foi realizada considerando o modelo estatístico:

$\mathrm{Y}_{\mathrm{ijkl}}=\mathrm{m}+\mathrm{P}_{\mathrm{i}}+\mathrm{N}_{\mathrm{j}}+\mathrm{PN}_{\mathrm{ij}}+\mathrm{T}_{\mathrm{k}}+\mathrm{PT}_{\mathrm{ik}}+\mathrm{NT}_{\mathrm{jk}}+\mathrm{PNT}_{\mathrm{ijk}}+$ $\mathrm{e}_{\mathrm{ijkl}}$, em que: $\mathrm{Y}_{\mathrm{ijkl}}=$ valores das variáveis avaliadas na unidade experimental que recebeu o probiótico i e o nível de proteína j no período $\mathrm{k}$ e na repetição $1 ; \mathrm{m}=$ constante geral; $\mathrm{P}_{\mathrm{i}}=$ efeito do probiótico $\mathrm{i}(\mathrm{i}=1,2) ; \mathrm{N}_{\mathrm{j}}=$ efeito do nível de proteína $\mathrm{j}(\mathrm{j}=1,2,3,4) ; \mathrm{PN}_{\mathrm{ij}}=$ efeito da interação probiótico $\times$ nível de proteína; $\mathrm{T}_{\mathrm{k}}=$ efeito do período $\mathrm{k}(\mathrm{k}=1,2) ; \mathrm{PT}_{\mathrm{ik}}$ $=$ efeito da interação probiótico $\times$ período $; \mathrm{NT}_{\mathrm{jk}}=$ efeito da interação nível de proteína $\times$ período; $\mathrm{PNT}_{\mathrm{ijk}}=$ efeito da interação probiótico $\times$ nível de proteína $\times$ período; $\mathrm{e}_{\mathrm{ijkl}}=$ erro aleatório associado a cada observação $\mathrm{Y}_{\mathrm{ijkl}}, \mathrm{e}_{\mathrm{ijkl}} \sim \mathrm{N}\left(0, \sigma^{2}\right)$.

$\mathrm{Na}$ análise estatística, assumiu-se que o efeito de período é fixo. Os graus de liberdade referentes aos níveis de proteína bruta foram desdobrados em polinômios ortogonais utilizando-se o programa SAEG, desenvolvido pela Universidade Federal de Viçosa-UFV (UFV, 1999).

As estimativas da exigência de proteína bruta, considerando as características de desempenho e de carcaça, foram obtidas mediante o uso dos modelos descontínuo LRP (Linear Response Plateau), citado por Braga (1983), e/ou quadrático e cúbico.

Adicionalmente, foram estabelecidos os primeiros componentes principais que envolvem as variáveis sob estudo com a finalidade de determinar a exigência que envolve simultaneamente mais de uma variável.

\section{Resultados e Discussão}

No decorrer do período experimental, a temperatura média registrada no interior do galpão foi: máxima $26,5^{\circ} \mathrm{Ce}$ mínima de $22,2^{\circ} \mathrm{C}$ para o período 1 ; e máxima $22,4^{\circ} \mathrm{C}$ e mínima de $17^{\circ} \mathrm{C}$ para o período 2 .

A adição do probiótico reduziu o consumo de ração (CR) e melhorou a conversão alimentar (CA) $(\mathrm{P}<0,05)$ na fase de 1 a 7 dias de idade, entretanto, nas demais fases, não influenciou o ganho de peso (GP) e a conversão alimentar das codornas (Tabela 2). Ressalta-se que, nessa fase (1 a 7 dias), a dosagem do probiótico fornecido foi o dobro do recomendado pelo fabricante, visando melhorar os resultados de desempenho, porém, essa tentativa não possibilitou atingir os objetivos propostos.

Oliveira et al. (2004) avaliaram o efeito do uso de antibióticos e probióticos na criação de codornas de postura (Coturnix coturnix japonica) nas primeiras semanas de vida e concluíram que em bom ambiente, com água e ração disponíveis e de boa qualidade, a adição de antibióticos e probióticos não têm efeito sobre o desempenho inicial.

A influência favorável da adição do probiótico no aumento da massa corpórea e a melhora na conversão alimentar de frangos de corte em situações com quantidades insuficientes de proteína (Mikulec et al., 1999) não foram

Tabela 2 - Desempenho e viabilidade de criação de codornas de corte de 1 a 35 dias alimentadas com rações contendo probiótico (Lactobacillus sp.)

\begin{tabular}{|c|c|c|c|c|}
\hline & $\begin{array}{l}\text { Idade } \\
\text { (dias) }\end{array}$ & Probiótico & Controle & $\mathrm{CV}(\%)^{1}$ \\
\hline Consumo de ração (g) & & $34,27 b$ & $39,84 \mathrm{a}$ & 9,20 \\
\hline Ganho de peso $(\mathrm{g})$ & 1 a 7 & 23,08 & 22,92 & 3,38 \\
\hline Conversão alimentar (g/g) & & $1,53 b$ & $1,80 \mathrm{a}$ & 10,22 \\
\hline Consumo de ração (g) & & 89,97 & 89,77 & 5,39 \\
\hline Ganho de peso $(\mathrm{g})$ & 7 a 14 & 38,90 & 39,23 & 5,11 \\
\hline Conversão alimentar (g/g) & & 2,38 & 2,34 & 3,34 \\
\hline Consumo de ração (g) & & 130,32 & 130,96 & 7,67 \\
\hline Ganho de peso (g) & 14 a 21 & 59,62 & 58,65 & 5,49 \\
\hline Conversão alimentar (g/g) & & 2,26 & 2,30 & 7,96 \\
\hline Consumo de ração (g) & & 151,77 & 151,51 & 3,73 \\
\hline Ganho de peso (g) & 21 a 28 & 48,14 & 48,79 & 6,98 \\
\hline Conversão alimentar (g/g) & & 3,16 & 3,12 & 6,41 \\
\hline Consumo de ração (g) & & 209,03 & 210,44 & 4,51 \\
\hline Ganho de peso (g) & 28 a 35 & 50,43 & 51,43 & 4,76 \\
\hline Conversão alimentar (g/g) & & 4,17 & 4,12 & 5,30 \\
\hline Consumo de ração (g) & & 463,59 & 471,02 & 3,89 \\
\hline Ganho de peso (g) & 1 a 35 & 172,03 & 172,23 & 2,46 \\
\hline Conversão alimentar (g/g) & & 2,72 & 2,75 & 3,63 \\
\hline Viabilidade de criação (g/g) & & 95,56 & 94,79 & 4,87 \\
\hline
\end{tabular}


constatadas neste experimento, uma vez que não houve interação significativa entre probiótico e nível de proteína bruta.

Em pesquisa realizada com frangos de corte por Kos \& Wittner (1982), esses autores verificaram que o probiótico teve efeito somente quando adicionado às dietas deficientes em metionina, lisina e triptofano. Entretanto, neste experimento as recomendações de lisina $(1,50 \%)$ foram atendidas somente nas rações contendo 25 e $30 \%$ de PB e $0,90 \%$ de metionina + cistina para o nível de $30 \%$ de $\mathrm{PB}$, de acordo com as recomendações de Barral (1994) para codornas na fase inicial de crescimento.

Os resultados obtidos nas pesquisas desenvolvidas por Kos \& Wittner (1982) e Mikulec et al. (1999) não foram comprovados neste trabalho, uma vez que as rações deficientes em PB e em lisina e metionina + cistina não apresentaram melhoras no desempenho de codornas de corte quando da administração do probiótico.

A viabilidade de criação de 1 a 35 dias (Tabela 2) também não foi influenciada pela adição do probiótico, porém, houve alto percentual de aves vivas, o que pode indicar as boas condições sanitárias em que as aves foram criadas, o que resulta em baixa condição de desafio sanitário.

Em situações de mínimo estresse e desafio, os probióticos não promovem resultados expressivos (Fox, 1988; Dale, 1992; Maruta, 1993), o que também poderia explicar a ausência de resultados benéficos, mesmo com os níveis nutricionais abaixo do recomendado.

Os níveis de PB tiveram efeito quadrático sobre o consumo de ração e o ganho de peso na fase de 1a 7 dias de idade, de modo que o consumo mínimo foi obtido no nível de 15,69\% e maior ganho de peso no nível de 33,74\%, de acordo com a regressão (Tabela 3 ).

Considerando o modelo descontínuo LRP, essa exigência ficou estimada em $22,70 \%$ e $26,95 \%$ para consumo de ração e ganho de peso, respectivamente.

Observou-se efeito linear dos níveis de proteína sobre a conversão alimentar ( 1 a 7 dias $)$, que melhorou à medida que se aumentou o nível de PB da dieta. Para peso médio aos 7 dias, as exigências determinadas foram de 34,53 e 27,11\%

Tabela 3 - Equações de regressão para as características de desempenho de codornas de corte e exigências nutricionais de proteína bruta pelo modelo de regressão e pelo modelo descontínuo LRP

\begin{tabular}{|c|c|c|c|c|}
\hline Variável & Idade & $\begin{array}{l}\text { Equação regressão para } \\
\text { cada nível de proteína bruta }\end{array}$ & Regressão & LRP \\
\hline Consumo de ração $(\mathrm{g})$ & & $\hat{y}=52,041-2,035 x+0,0648 x^{2} ; R^{2}=1,00$ & 15,69 & 22,70 \\
\hline Ganho de peso $(\mathrm{g})$ & 1 a 7 dias & $\hat{y}=-20,245+2,976 x-0,0441 x^{2} ; R^{2}=1,00$ & 33,74 & 26,95 \\
\hline Conversão alimentar (g/g) & & $\hat{\mathrm{y}}=2,481-0,0363 \mathrm{x} ; \mathrm{R}^{2}=0,95$ & - & - \\
\hline Peso médio $(\mathrm{g})$ & 7 dias & $\hat{y}=-9,72+2,84 x-0,041 x^{2} ; R^{2}=1,00$ & 34,53 & 27,11 \\
\hline Consumo de ração (g) & & $\hat{\mathrm{y}}=42,162+2,120 x ; R^{2}=0,98$ & - & - \\
\hline Ganho de peso $(\mathrm{g})$ & 7 a 14 dias & $\hat{y}=-38,63+5,576 x-0,0889 x^{2} ; R^{2}=1,00$ & 31,36 & 26,26 \\
\hline Conversão alimentar (g/g) & & $\hat{y}=6,189-0,3075 x+0,0058 x^{2} ; R^{2}=1,00$ & 26,51 & 21,95 \\
\hline Peso médio $(\mathrm{g})$ & 14 dias & $\hat{y}=-45,326+8,149 x-0,124 x^{2} ; R^{2}=1,00$ & 32,86 & 26,68 \\
\hline Consumo de ração (g) & & $\hat{y}=95,277+1,5719 x$ & - & - \\
\hline Ganho de peso $(\mathrm{g})$ & 14 a 21 dias & $\hat{y}=-55,800+9,051 x-0,165 x^{2} ; R^{2}=1,00$ & 27,43 & 22,63 \\
\hline Conversão alimentar (g/g) & & $\hat{y}=5,649-0,274 x+0,0052 x^{2 ;} R^{2}=1,00$ & 26,35 & 21,77 \\
\hline Peso médio $(\mathrm{g})$ & 21 dias & $\hat{y}=-100,01+17,12 x-0,29 x^{2 ;} R^{2}=1,00$ & 29,78 & 23,56 \\
\hline Consumo de ração (g) & & $\hat{y}=95,171+2,5098 x ; R^{2}=0,99$ & - & - \\
\hline Ganho de peso $(\mathrm{g})$ & 21 a 28 dias & $\hat{y}=-7,906+4,486 x-0,0829 x^{2} ; R^{2}=0,99$ & 27,06 & 21,56 \\
\hline Conversão alimentar $(\mathrm{g} / \mathrm{g})$ & & $\hat{\mathrm{y}}=5,582-0,231 \mathrm{x}+0,0051 \mathrm{x}^{2} ; \mathrm{R}^{2}=0,81$ & 22,65 & 16,75 \\
\hline Peso médio (g) & 28 dias & $\hat{y}=-103,79+21,35 x-0,37 x^{2} ; R^{2}=1,00$ & 29,14 & 23,14 \\
\hline Consumo de ração $(\mathrm{g})$ & & $\hat{y}=26,416+13,3649 x-0,2184 x^{2} ; R^{2}=1,00$ & 30,60 & 26,29 \\
\hline Ganho de peso $(\mathrm{g})$ & 28 a 35 dias & $\hat{y}=-213,526+37,974 x-1,732 x 2+0,025 x^{3} ; R^{2}=1,00$ & 028,29 & - \\
\hline Conversão alimentar (g/g) & & $\hat{\mathrm{y}}=1,991+0,0959 x ; \mathrm{R}^{2}=0,91$ & - & - \\
\hline Peso médio $(\mathrm{g})$ & 35 dias & $\hat{y}=-66,80+23,04 x-0,41 x^{2} ; R^{2}=1,00$ & 28,06 & 22,23 \\
\hline Consumo de ração (g) & & $\hat{y}=57,050+29,687 x-0,479 x^{2} ; R^{2}=1,00$ & 30,99 & 26,45 \\
\hline Ganho de peso $(\mathrm{g})$ & 1 a 35 dias & $\hat{y}=522,229-43,62 x+1,738 x^{2}-0,0219 x^{3} ; R^{2}=1,00$ & 36,24 & - \\
\hline Conversão alimentar (g/g) & & $\hat{y}=4,440-0,144 x+0,00283 x^{2} ; R^{2}=0,97$ & 25,44 & 20,26 \\
\hline
\end{tabular}


de $\mathrm{PB}$, respectivamente, segundo o modelo quadrático e o modelo descontínuo LRP.

Dos 7 aos 14 dias de idade, o consumo de ração aumentou de forma linear, de acordo com os níveis de PB. Efeito quadrático dos níveis de PB sobre o ganho de peso foi verificado, com pontos de máximo peso das codornas para dietas, contendo $31,36 \%$ de PB. Novamente, considerando o LRP, a exigência reduziu para $26,26 \%$ de PB.

Para a conversão alimentar, nessa fase, foi estimada exigência de PB de 26,51 e 21,95\%, respectivamente, de acordo com os modelos de regressão e LRP. Resultados diferentes foram obtidos por Rezende et al. (2004), que não encontraram diferenças no ganho de peso, consumo de ração e na conversão alimentar de codornas francesas aos 14 dias de idade ao trabalharem com níveis entre 20,5 e 23,5\% de PB. Entretanto, esses resultados provavelmente estão relacionados aos baixos níveis de $\mathrm{PB}$, à genética e à pequena variação nas dietas experimentais utilizadas pelos autores.

Os resultados de consumo de ração e conversão alimentar diferem dos resultados obtidos por Corrêa et al. (2004a,b), que não verificaram efeito dos níveis de PB sobre o consumo de ração na fase de 7 a 14 dias, no entanto, verificou-se efeito linear dos níveis de PB sobre a conversão alimentar de codornas de corte. Efeito linear do nível de PB sobre o ganho de peso foi encontrado por Corrêa et al. (2004a) e Oliveira et al. (2002), no entanto, Corrêa et al. (2004b) observaram efeito quadrático para as dietas com $2.900 \mathrm{kcal} \mathrm{EM} / \mathrm{kg}$, cuja exigência foi de $27,40 \%$ e linear para a dieta com $3.100 \mathrm{kcal} \mathrm{EM} / \mathrm{kg}$.

As exigências determinadas para peso médio aos 14 dias (Tabela 3), respectivamente, pelo modelo quadrático e descontínuo LRP, foram de 32,86 e 26,68\% de PB. Diferentemente dos resultados obtidos neste experimento, Corrêa et al. (2004b) encontraram exigências de PB, segundo o modelo quadrático, para peso acumulado dos 7 aos 14 dias, de $26,60 \%$ PB, com dietas que contém $2.900 \mathrm{kcal} \mathrm{EM} / \mathrm{kg}$.

Dos 14 aos 21 dias de idade, efeito linear dos níveis de PB foi novamente encontrado para o consumo de ração e efeito quadrático para o ganho de peso e a conversão alimentar (Tabela 3). Esses resultados demonstram, respectivamente, ponto de máximo ganho de peso e mínima conversão alimentar para as dietas que contém, respectivamente, 27,43 e 26,35\% de PB. Com o uso do modelo descontínuo LRP, houve redução na exigência de PB para 22,63 e 21,77\%, respectivamente, para essas características de desempenho.

Efeitos quadrático do nível de PB sobre o consumo de ração e ganho de peso, e linear para a conversão alimentar na fase de 15 a 21 dias foram encontrados por Corrêa et al. (2004a), com aumento do consumo até o nível de 25,24\%, e ponto de máximo peso das codornas de corte no nível de $26,38 \%$ de $\mathrm{PB}$, o que difere dos resultados encontrados neste trabalho.

As estimativas de exigência de $\mathrm{PB}$ para peso médio aos 21 dias pelo modelo quadrático e pelo modelo descontínuo foram, respectivamente, de 29,78 e 23,56\% de PB.

Na fase dos 21 aos 28 dias de idade, o consumo de ração, o ganho de peso e a conversão alimentar foram influenciados, respectivamente, de forma linear, quadrática e quadrática pelos níveis de PB. O máximo ganho de peso e a melhor conversão alimentar foram obtidos com 27,06 e $22,65 \%$ de PB. De acordo com o modelo descontínuo LRP, a exigência para máximo ganho de peso e melhor conversão alimentar reduziu para 21,56 e 16,75\%, respectivamente.

Nessa fase, a exigência para máximo ganho de peso em codornas de corte foi superior à encontrada por Corrêa et al. (2004a), que verificaram exigência de 26,09\% de PB. Entretanto, esses autores não verificaram efeito dos níveis $(22,24,26$ e $28 \%)$ de PB sobre o consumo de ração na fase de 22 a 28 dias.

As estimativas de exigência de $\mathrm{PB}$ para peso médio aos 28 dias foram semelhantes aos resultados obtidos para peso médio aos 21 dias e ao obtido no nível de 29,14 e $23,14 \%$ de $\mathrm{PB}$, respectivamente, pelos modelos quadrático e descontínuo.

O consumo de ração e o ganho de peso na fase de 28 a 35 dias sofreram, respectivamente, influência quadrática e cúbica dos níveis de PB (Tabela 3), com máximo consumo e máximo ganho nos níveis de 30,60 e 28,29\% de PB. Efeito linear positivo foi obtido para a conversão alimentar, que piorou com o aumento dos níveis. Nessa fase, Corrêa et al. (2004a,b) não encontraram efeito dos níveis de PB sobre o consumo de ração, em contrapartida, Corrêa et al. (2004a) encontraram efeito linear para a conversão alimentar e efeito quadrático para o ganho de peso no nível de $24,05 \%$ de PB, inferior ao obtido nesse experimento.

Efeito linear negativo foi verificado por Oliveira et al. (2002) para o ganho de peso e efeito linear positivo para a conversão alimentar na fase de 27 a 38 dias, assim nessa fase, à medida que aumentam os níveis de $\mathrm{PB}$, há decréscimo no ganho de peso e piora na conversão alimentar.

Os resultados de peso médio aos 35 dias (Tabela 3) indicam efeito quadrático dos níveis de $\mathrm{PB}$, com exigência estimada em $28,06 \%$ de PB, mas, de acordo com o modelo LRP, essa exigência ficou estimada em 22,23\%.

Segundo Kirkpinar \& Oguz (1995), codornas japonesas alimentadas com $30 \%$ de proteína bruta em dietas isocalóricas 
(2.800 $\mathrm{kcal} \mathrm{EM} / \mathrm{kg})$, porém com seis níveis protéicos $(16,20$, $22,25,28$ e $30 \%$ ), apresentaram maior peso vivo no 35 o dia de idade.

Na fase total (1 a 35 dias), o consumo de ração, o ganho de peso e a conversão alimentar comprovaram, respectivamente, efeito quadrático, cúbico e quadrático dos níveis de PB sobre essas características (Tabela 3), e ocorreram aumento do consumo de ração até o nível de 30,99\% de PB, máximo ganho de peso com o nível de 36,24\% e melhor conversão alimentar no nível de 25,44\% de PB. Considerando o modelo descontínuo LRP, as estimativas de PB foram de 26,35 e $20,26 \%$ para o consumo de ração e a conversão alimentar, respectivamente.

Hyánová et al. (1997) verificaram que os níveis de proteína bruta (26 vs. $23,8 \%$ fase inicial e 21,6 vs. $19,5 \%$ fase de crescimento) na dieta de codornas japonesas criadas para a produção de carne não afetaram o peso corporal, o consumo de ração e a conversão alimentar na fase de 1 a 35 dias de idade, e que portanto, os menores níveis de proteína bruta podem ser recomendados para uso prático. Esses autores compararam somente dois níveis de PB, o que culminou na recomendação de baixo nível de PB.

As estimativas de exigência de $\mathrm{PB}$ variaram muito para cada variável estudada pelos modelos quadrático e/ou cúbico, e o modelo descontínuo (Tabela 3 ).

A divergência entre exigências protéicas pode ser atribuída a diferenças entre períodos, níveis de energia metabolizável, genética, condições ambientais, entre outros (Rezende et al., 2004), mas, de maneira geral, indica a necessidade de formulação de rações diferenciadas para cada fase.

Corrêa et al. (2004a) concluíram que a exigência de proteína bruta para máximo ganho de peso de codornas de corte européias é superior a 28\% para a fase de 7 a 14 dias, $26 \%$ para a fase de 15 a 28 dias e $24 \%$ para a fase de 29 a 35 dias. Melhor desempenho de codornas japonesas (machos) criadas para a produção de carne foi encontrado por Oliveira et al. (2002), de 26\% de PB para a fase de 5 a 27 dias de idade e de $18 \%$ para a fase de 27 a 38 dias. Por outro lado, Más et al. (2004a) não encontraram efeito dos níveis de proteína bruta, de 21,5 a $26 \%$ ( 1 a 21 dias) e de 17,5 a $22 \%$ (22 a 49 dias), sobre o desempenho na fase de 1 a 35 dias de idade.

As necessidades de PB propostas por Barral et al. (1994) são divididas em duas fases: de 26 a $28 \%$ de PB para a fase de 1 a 21 dias e de 22 a $24 \%$ para a fase de 22 até o abate.

Neste trabalho, para o peso vivo médio aos 7, 14, 21, 28 e 35 dias de idade, houve redução das estimativas de exigência, de acordo com o LRP. Até os 14 dias, as estima- tivas de exigência foram de $27 \%$ de $\mathrm{PB}$ e, a partir desta idade, houve redução na exigência de proteína, que pode estar entre 22 e $24 \%$, denotando a importância da utilização de rações diferenciadas por fases para codornas de corte, assim como em frangos de corte.

A adição do probiótico associado a diferentes níveis de PB não influenciou o rendimento de carcaça e de cortes (Tabela 4). Trabalhos conduzidos por Henrique et al. (1998a,b), Loddi et al. (2000; 2002), Maiorka et al. (2001) e Vargas Jr. et al. (2002) também não comprovaram melhoras nas características de carcaça com o uso do probiótico.

Por outro lado, Corrêa et al. (2003), avaliando poliprobiótico constituído de cepas de Lactobacillus acidophilus e casei, Streptococcus salivarium e faecium, Bacillus subtilis e toyoi e Saccharomyces cerevisae e Pelicano et al. (2003), avaliando diferentes probióticos adicionados na ração (Bacillus subtilis e/ou Bacillus licheniformis, ou Saccharomyces cerevisiae) e/ou água de bebida (Lactobacillus reuteri e johnsonii), verificaram, respectivamente, maior rendimento de coxa e pernas em frangos de corte ao final do período experimental.

Para o rendimento de carcaça, a exigência de $\mathrm{PB}$, de acordo com o modelo quadrático, ficou estimada em 23,53\%, entretanto, pelo LRP, a estimativa reduziu para $17,13 \%$ de PB (Tabela 5).

Más et al. (2004b), avaliando diferentes níveis de PB, variando de 21,5 a $26 \%$ no período de 1 a 21 dias e de 17,5 a $22 \%$, no período de 22 a 49 dias, não encontraram influência do nível de PB sobre o rendimento de carcaça de codornas de corte, no entanto, houve pequena variação nos níveis de $\mathrm{PB}$, o que poderia explicar a ausência do efeito.

$\mathrm{O}$ rendimento de peito apresentou comportamento cúbico, o que resultou na exigência de 26,47\% de PB, discordando dos resultados obtidos por Corrêa et al. (2004c, 2005), que não verificaram efeito dos níveis de PB $(22,24,26$ e $28 \%)$ sobre o rendimento desse corte.

As estimativas de exigência de $\mathrm{PB}$ para os rendimentos de asa e dorso pelo modelo quadrático foram, respecti-

Tabela 4 - Rendimento de cortes de codornas de corte aos 35 dias de idade alimentadas com rações contendo probiótico à base de Lactobacillus sp.

\begin{tabular}{|c|c|c|c|}
\hline Corte $(\%)$ & Com probiótico & Sem probiótico & $\mathrm{CV} \%$ \\
\hline Carcaça & 69,93 & 70,28 & 2,80 \\
\hline Peito & 39,66 & 40,34 & 2,49 \\
\hline Asa & 6,77 & 6,96 & 3,05 \\
\hline Perna & 23,63 & 23,61 & 2,12 \\
\hline Dorso & 28,63 & 28,02 & 2,57 \\
\hline Gordura & 1,52 & 1,43 & 17,31 \\
\hline
\end{tabular}

Não-significativo pelo teste $\mathrm{F}(\mathrm{P}>0,05)$. 
Tabela 5 - Equações de regressão para o rendimento de cortes de codornas de corte aos 35 dias de idade alimentadas com rações contendo probiótico à base de Lactobacillus sp.

\begin{tabular}{llcc}
\hline Corte $(\%)$ & Equação de regressão em cada nível de PB & Regressão & LRP \\
\hline Carcaça & $\hat{y}=54,902+1,374 x-0,0292 x^{2} ; R^{2}=0,69$ & 23,53 & 17,13 \\
Peito & $\hat{y}=-42,572+11,064 x-0,479 x^{2}+0,0068 x^{3} ; R^{2}=1,00$ & 26,47 & - \\
Asa & $\hat{y}=11,446-0,358 x+0,00648 x^{2} ; R^{2}=0,99$ & 27,62 & - \\
Perna & $\hat{y}=24,638-0,0452 x ; R^{2}=0,82$ & 22,34 & - \\
Dorso & $\hat{y}=19,837-0,613 x+0,0136 x^{2} ; R^{2}=0,70$ & - & - \\
Gordura & $\hat{y}=-0,131+0,0713 x ; R^{2}=0,96$ & -36 \\
\hline
\end{tabular}

vamente, de 27,62 e 22,54\% de PB e, de acordo com o modelo descontínuo, de 23,34 e 16,36\% de PB, respectivamente, o que indica exigência superior para o rendimento de asa.

Para o rendimento de pernas, observou-se efeito linear negativo e para o rendimento de gordura, efeito linear positivo dos níveis de PB (Tabela 5).

Corrêa et al. (2004c) encontraram efeito quadrático do nível de PB sobre o rendimento de pernas em trabalho com dietas com $2.900 \mathrm{kcal} \mathrm{EM} / \mathrm{kg}$ somente para os machos, que apresentaram máximo rendimento quando mantidos com dietas com 24,28\% de PB, enquanto para as fêmeas, não foi verificado efeito dos níveis de PB.

O rendimento de gordura não foi afetado pelos níveis de PB (22, 24, 26 e 28\%) em pesquisa desenvolvida por Corrêa et al. (2005). Wyatt et al. (1982), no entanto, encontraram relação positiva e significante entre o peso corporal e a porcentagem de gordura na carcaça, enquanto Costa et al. (2001) verificaram maior deposição de gordura abdominal em frangos de corte alimentados com menores níveis de $\mathrm{PB}$ na ração, todavia, os níveis de $\mathrm{PB}$ utilizados por esses autores variaram de 20 a $22,5 \%$ no período de 1 a 21 dias e de 17,5 a $19,5 \%$ no período de 22 a 42 dias e as rações com menores níveis de PB foram suplementadas com aminoácidos sintéticos (lisina, metionina e treonina).

Entre os componentes principais estimados, aquele que envolve peso médio aos 35 dias (PM35), ganho de peso de 1 a 35 dias (GP135) e conversão alimentar de 1 a 28 (CA128) dias foi escolhido para determinação da exigência nutricional de $\mathrm{PB}$ por responder por $94,61 \%$ da variação.

Ao usar esse componente principal, procedeu-se à análise da mesma forma que para as variáveis isoladamente e não houve efeito do probiótico nem da interação probiótico $\times$ nível.

A equação ajustada para o componente principal em cada nível de PB foi $\hat{y}=-18,338+1,445 x-0,0264 x^{2}$, o que resultou em estimativa de exigência igual a $27,37 \%$. A aplicação do modelo descontínuo LRP indicou estimativa de $21,91 \%$ de PB.
Os resultados deste estudo sugerem a necessidade de formulação de rações diferenciadas para cada fase de codornas de corte, uma vez que, até os 14 dias, as exigências de PB foram de $27 \%$ e aos 21, 28 e 35 dias, de 22 a $24 \%$.

\section{Conclusões}

Nas condições ambientais em que as codornas foram criadas, a adição de probiótico à base de Lactobacillus sp. não influenciou o desempenho, o rendimento de carcaça, a exigência nutricional de proteína bruta de codornas de corte. As estimativas de exigência de proteína até os 14 dias de idade foram de $27 \%$ e, a partir desta idade, reduziram para 22 a $24 \%$.

\section{Literatura Citada}

BARRAL, A.D. Manual de la codorniz: cria industrial y para la caza. Lleida: Dilagro, 1994. 268p.

BRAGA, J.M. Avaliação da fertilidade do solo (ensaios de campo). Imprensa Universitária, n.156, p.15-20, 1983.

CORRÊA, G.S.S.; SILVA, M.A.; FONTES, D.O. et al. Efeito de diferentes níveis de proteína e energia sobre o rendimento de carcaça de codornas européias. Arquivo Brasileiro de Medicina Veterinária e Zootecnia, v.57, n.2, p.266-271, 2005.

CORRÊA, A.B.; CORRÊA, G.S.S.; SILVA, M.A. et al. Efeito de diferentes níveis de proteína bruta e energia metabolizável sobre características de codornas de corte avaliadas durante a fase de crescimento. In: REUNIÃO ANUAL DA SOCIEDADE BRASILEIRA DE ZOOTECNIA, 41., 2004, Campo Grande, MS. Anais... Campo Grande: Sociedade Brasileira de Zootecnia, [2004a]. (CD-ROM).

CORRÊA, A.B.; CORRÊA, G.S.S.; SILVA, M.A. et al. Desempenho produtivo de codornas tipo carne alimentadas com dietas contendo diferentes níveis de proteína bruta e energia metabolizável. In: REUNIÃO ANUAL DA SOCIEDADE BRASILEIRA DE ZOOTECNIA, 41., 2004, Campo Grande. Anais... Campo Grande: Sociedade Brasileira de Zootecnia, [2004b]. (CD-ROM).

CORRÊA, G.S.S.; SILVA, M.A.; CORRÊA, A.B. et al. Rendimento de carcaça de codornas de corte alimentadas com dietas com diferentes níveis de proteína bruta e energia metabolizável. In: REUNIÃO ANUAL DA SOCIEDADE BRASILEIRA DE ZootecniA, 41., 2004, Campo Grande. Anais... Campo Grande: Sociedade Brasileira de Zootecnia, [2004c]. (CD-ROM).

CORRÊA, G.S.S.; GOMES, A.V.C.; CORRÊA, A.B. et al. Efeito de antibiótico e probióticos sobre o desempenho e rendimento de 
carcaça de frangos de corte. Arquivo Brasileiro de Medicina Veterinária e Zootecnia, v.55, n.4, p.467-473, 2003.

COSTA, F.G.P.; ROSTAGNO, H.S.; ALBINO, L.F.T. et al. Níveis dietéticos de proteína bruta para frangos de corte de 1 a 21 e 22 a 42 dias de idade. Revista Brasileira de Zootecnia, v.30, n.5, p.1498-1505, 2001.

DALE, N. Probióticos para aves. Avicultura Professional, v.10, p.88-89, 1992.

DILWORTH, B.C.; DAY, E.J. Lactobacillus cultures in broiler diets. Poultry Science, v.57, p.1101, 1978. (Abstract).

FOX, S.M. Probiotics: intestinal inoculants for production animals Veterinary Medicine, v.83, p.806-830, 1988

FULLER, R. Probiotics: the scientific basis. London: Chapman \& Hall, 1989. 307p.

HENRIQUE, A.P.F.; FARIA, D.E.; FRANZOLIN, R. et al. Uso de probióticos e antibióticos como promotores de crescimento para frangos de corte. In: REUNIÃO ANUAL DA SOCIEDADE BRASILEIRA DE ZOOTECNIA, 35., 1998, Botucatu. Anais... Botucatu: Sociedade Brasileira de Zootecnia, [1998a]. (CD-ROM).

HENRIQUE, A.P.F.; FARIA, D.E.; FRANZOLIN, R. et al. Efeito de ácido orgânico, probiótico e antibiótico sobre o desempenho e rendimento de carcaça de frangos de corte. In: REUNIÃO ANUAL DA SOCIEDADE BRASILEIRA DE ZOOTECNIA, 35. 1998, Botucatu. Anais... Botucatu: Sociedade Brasileira de Zootecnia, [1998b]. (CD-ROM).

HYÁNOVÁ, L.; DEDKOVÁ, L.; KNÍZETOVÁ, H. et al. Responses in growth, food intake and food conversion efficiency to different dietary protein concentrations in meat-type lines of Japanese quail. British Poultry Science, v.38, p.564-570, 1997.

KIRKPINAR, F.; OGUZ, I. Influence of various dietary protein levels on carcase composition in the male Japanese quail (Coturnix coturnix japonica). British Poultry Science, v.36, p.605-610, 1995.

KOS, K.; WITTNER, V. Use of probiotics in the nutrition of the fattening chicks. Praxis Veterinary, v.30, p.283-286, 1982.

LODDI, M.M.; TUCCI, F.M.; HANNAS, M.I. et al. Probióticos, mananoligossacarídeos + ácidos orgânicos em dietas de frangos. In: REUNIÃO ANUAL DA SOCIEDADE BRASILEIRA DE ZOOTECNIA, 39., 2002, Recife. Anais... Recife: Sociedade Brasileira de Zootecnia, [2002]. (CD-ROM).

LODDI, M.M.; GONZALES, E.; TAKITA, T.S. et al. Uso de probiótico e antibiótico sobre o desempenho, o rendimento e a qualidade de carcaça de frangos de corte. Revista Brasileira de Zootecnia, v.29, n.4, p.1124-1131, 2000.

MAIORKA, A.; SANTIN, E.; SUGETA, S.M. et al. Utilização de prebióticos, probióticos ou simbióticos em dietas para frangos. Revista Brasileira de Ciência Avícola, v.3, n.1, 2001. Disponível em: <http://www.scielo.br> Acesso em: 5/3/2006.

MARUTA, K. Probióticos e seus benefícios. In: CONFERÊNCIA APINCO DE CIÊNCIA E TECNOLOGIA AVÍCOLAS, 1993, Santos. Anais... Santos: Fundação Apinco de Ciência e Tecnologias Avícolas, 1993. p.203-219.
MÁS, H.A.R.; BERTECHINI, A.G.; FASSANI, E.J. et al. Efeito da redução do nível protéico da ração sobre o desempenho de codornas de corte. In: SIMPÓSIO DE COTURNICULTURA, 2., 2004, Lavras, MG. Anais... Lavras: Universidade Federal de Lavras, [2004a]. (CD-ROM).

MÁS, H.A.R.; FASSANI, E.J.J.; BRITO, J.A.G. et al. Rendimento de carcaça de codornas de corte submetidas a diferentes níveis protéicos e idades de abate. In: SIMPÓSIO DE COTURNICULTURA, 2., 2004, Lavras. Anais... Lavras: Universidade Federal de Lavras, [2004b]. (CD-ROM).

MIKULEC, Z.; SERMAN, V.; MAS, N. et al. Effect of probiotic on production results of fattened chickens fed different quantities of protein. Veterinarski Arhiv, v.69, n.4, p.199-209, 1999.

MURAKAMI, A.E.; ARIKI, J. Produção de codornas japonesas. Jaboticabal: FUNEP, 1998. 79p.

OLIVEIRA, N.T.E.; SILVA, M.A.; SOARES, R.T.R.N. et al. Exigências de proteína bruta e energia metabolizável para codornas japonesas machos criadas para a produção de carne. Arquivo Brasileiro de Medicina Veterinária e Zootecnia, v.54, n.2, 2002. Disponível em: <http://www.scielo.br> Acesso em: $5 / 4 / 2006$

OLIVEIRA, B.L.; OLIVEIRA, D.D.; OLIVEIRA, A.I.G. Utilização de probióticos e antibióticos na fase inicial da criação de codornas (Coturnix coturnix japonica). In: SIMPÓSIO DE COTURnicultura, 2004, Lavras. Anais... Lavras: [s.n.], 2004. (CD-ROM).

PELICANO, E.R.L.; SOUZA, P.A.; SOUZA, H.B.A. et al. Effect of different probiotics on broiler carcass and meat quality. Revista Brasileira de Ciência Avícola, v.5, n.3, p.207-214, 2003.

REZENDE, M.J.M.; FLAUZINA, L.P.; McMANUS, C. et al. Desempenho produtivo e biometria das vísceras de codornas francesas alimentadas com diferentes níveis de energia metabolizável e proteína bruta. Acta Scientiarium, v.26, n.3, p.353-358, 2004.

ROSTAGNO, H.S.; ALBINO, L.F.T.; DONZELE, J.L. et. al. Tabelas brasileiras para aves e suínos: composição de alimentos e exigências nutricionais de aves e suínos. Viçosa, MG: Editora UFV, 2005. 141p.

SMITH, M.O. Parts yield of broilers reared under cycling high temperatures. Poultry Science, v.72, p.1146-1150, 1993.

UNIVERSIDADE FEDERAL DE VIÇOSA - UFV. Manual de utilização do programa SAEG - Sistema para Análise Estatísticas e Genéticas. Viçosa, MG: 1999. 59p.

VARGAS JR., J.G.; TOLEDO, R.S.; ALBINO, L.F. et al. Características de carcaça de frango de corte, submetidos a rações contendo probióticos, prebióticos e antibióticos. In: REUNIÃO ANUAL DA SOCIEDADE BRASILEIRA DE ZOOTECNIA, 39., 2002, Recife. Anais... Recife: Sociedade Brasileira de Zootecnia, [2002]. (CD-ROM).

WYATT, J.F.M.; SIEGEL, P.B.; CHERRY, J.A. Phenotypic relationships between adiposity, breast weight, and body weight in female Japanese quail. Poultry Science, v.61, p.643-646, 1982. 